\title{
La importancia de la información contable ante la incertidumbre del Covid-19, en las Mipymes en el entorno de los negocios en la región 6.
}

The importance of accounting information in the face of the uncertainty of Covid-19, in MSMEs in the business environment in the region 6.

Edison Becerra Molina. ${ }^{1}$, Yolanda Jaramillo Calle. ${ }^{2} \&$ Pedro Astudillo Arias. ${ }^{3}$

DOI: $\underline{\text { https://doi.org/10.33262/visionariodigital.v5i3.1779 }}$

\begin{abstract}
.
Introduction. Accounting is the science that deals with economic and financial activities in a chronological and quantified way to classify, record, summarize them in financial statements and then analyze and interpret them. Objective. Formulate a strategic proposal for the effective management of accounting information, given the uncertainty of COVID-19 in MSMEs in the business environment in the region 6. Methodology. The research design started from the positivist research paradigm, type of research, nonexperimental and cross-sectional field design with documentary support, descriptive research level, the population was 77,289 and the sample of 471, the survey technique was used, By means of the questionnaire instrument, it consisted of 8 items, it was validated by the judgment of three experts with experience in the area of accounting, entrepreneurship and methodology, qualifying clarity, coherence, relevance, score, qualification and indicator. Results. With respect to production, the respondents maintained in $24.31 \%$, that it is important that companies choose to diversify their products, that it is necessary to review profitability, $22.23 \%$, to evaluate the possible scenarios that may affect the businesses, lack of liquidity $19.39 \%$, since they do not have

\footnotetext{
1 Universidad Católica de Cuenca, Carrera de Contabilidad y auditoría, provincia Azuay, código, jbecerram@ucacue.edu.ec, Orcid ID:000-0002-6397-9493

${ }_{2}^{2}$ Universidad Católica de Cuenca, Carrera de Contabilidad y auditoría, provincia Azuay, código, cjaramillo@ucacue.edu.ec, Orcid ID:0000-0003-3088-8322

${ }^{3}$ Universidad Católica de Cuenca, Carrera de Contabilidad y auditoría, provincia Azuay, código, pastudillo@ucacue.edu.ec, Orcid ID:0000-0003-4639-0318
} 
enough money to meet liabilities and expenses, the company must close its doors, employment is represented with $19.02 \%$, it is important to emphasize that many of the businesses had to cut staff and affected the income of employees and the employer, $13.45 \%$ argue that there is a budget gap and that there was an imbalance in their planning, and $1.80 \%$ of businesses should be responsible with the use of the capital they must manage. Conclution. It was concluded that the different actions undoubtedly generated an economic impact both for the liquidity of the companies and those who depended on them.

Keywords: COVID-19, economy, MSMEs, recession, accounting information.

\section{Resumen.}

Introducción. La contabilidad es la ciencia que trata de las actividades económicas y financieras en forma cronológica y cuantificada para clasificarlas, registrarlas, resumirlas en estados financieros y luego analizarlas e interpretarlas. Objetivo. Formular una propuesta estratégica para el manejo eficaz de la información contable, ante la incertidumbre del COVID-19 en las Mipymes en el entorno de los negocios en la región 6. Metodología. El diseño de la investigación partió del paradigma de investigación positivista, tipo de investigación diseño de campo no experimental y transversal con apoyo documental, nivel de investigación descriptiva, la población fue de 77.289 y la muestra de 471, se utilizó la técnica de la encuesta, mediante el instrumento del cuestionario, constó con 8 items, fue validado mediante el juicio de tres expertos con experiencia en el área de contabilidad, emprendimiento y metodología, calificando claridad, coherencia, relevancia, puntaje, calificación e indicador. Resultados. Con respecto a la producción los encuestados sostuvieron en un $24,31 \%$, que es importante que las empresas opten por diversificar sus productos, que es necesario revisar la rentabilidad, el 22,23\%, para evaluar los posibles escenarios que pueden afectar a los negocios, falta de liquidez el 19,39\%, ya que no cuentan con dinero suficiente para afrontar pasivos y gastos, la empresa debe cerrar sus puertas, el empleo está representada con un 19,02\%, es importante recalcar que muchos de los negocios tuvieron que hacer recorte de personal y afectaron los ingresos de los empleados y del empleador, el 13,45\% sostienen que existe un desfase presupuestario y que ocurrió un desequilibrio en sus planificaciones, y un 1,80\% de los negocios deben ser responsables con la utilización del capital que deben manejar. Conclusión. Se concluyó que las diferentes acciones sin duda generaron un impacto económico tanto para la liquidez de las empresas como en quienes dependían de las mismas.

Palabras claves: COVID-19, economía, Mipymes, recesión, información contable.

\section{Introducción.}

Los efectos de la pandemia por la propagación del COVID-19 están sacudiendo las estructuras socioeconómicas a nivel local, regional, nacional y mundial. Los impactos se estiman en cifras astronómicas de pérdidas de vidas y empleos, el gobierno y el sector 
productivo, están desplegando medidas sanitarias y económicas para frenar el avance de la epidemia con gran incertidumbre aún sobre la duración del periodo de emergencia sanitaria y las consecuencias reales de la pandemia sobre la población y el tejido productivo.

De allí que es importante que tanto las micro, pequeñas y medianas empresas, desplieguen esfuerzos para apoyar la emergencia sanitaria, por la pandemia, por consiguiente, las Mipymes tienen la imperiosa necesidad de analizar los estados financieros y su oportunidad y confiabilidad de las cifras, considerando temas en materia de contabilidad, finanzas, tributos y demás disposiciones, en articulación con el entorno de los negocios, societario y laboral y las disposiciones que el gobierno ha emitido para tratar de aliviar en algo la situación financiera de liquidez en las empresas.

La presente investigación es parte del proyecto de investigación denominado "La importancia de la información contable y financiera ante la incertidumbre del COVID-19 en las Mipymes en el entorno de los negocios en la región 6", el mismo que se justifica porque contribuirá desde una perspectiva teórica académica a dar salida a los problemas de las Mipymes, desde el punto de vista del contenido contable, las microempresas pueden mantenerse y no cerrar sus puertas. La contabilidad es la columna vertebral de las finanzas en el mundo de los negocios, sin ella no tendrían forma de optimizar sus recursos, sus ganancias, sus ingresos, sus egresos; en las pequeñas y medianas empresas, es necesario analizar los estados financieros, considerando lo que técnicamente nos dice la normativa contable, es decir las Norma Internacional de Contabilidad- NIC, en correspondencia con las Normas Internacionales de Información Financiera- NIIF, examinando los componentes principales de las cuentas de activo, pasivo, patrimonio, ingresos y gastos para tener una clara noción del cumplimiento de lo que técnicamente establecen las normas contables y las resoluciones tributarias, dispuestos por el Servicio de Rentas Internas, societarios, por la Súper Intendencia de Compañías, financieros, por la Junta de Política y Regulación Monetaria, y los acuerdos ministeriales en materia laboral, emitidos por el Ministerio de trabajo y la Asamblea Nacional.

\section{Metodologia.}

Esta investigación se enmarcó en el ámbito de la contabilidad, ya que se tuvo conciencia que existió una realidad que descubrir, construir e interpretar, contempla su propia metodología, por cuanto comúnmente se aplica únicamente al mundo de los negocios. La ruta metodológica parte del paradigma de investigación positivista, tipo de investigación diseño de campo no experimental y transeccional o transversal con apoyo documental, nivel de investigación fue la investigación descriptiva, Arias (2016), señala que: "La investigación descriptiva consiste en la caracterización de un hecho, fenómeno, individuo o grupo, con el fin de establecer su estructura o comportamiento" (p.24). De allí que se corresponde con el nivel descriptivo en función del objetivo general planteado, la población estuvo estructurada por tres sectores escogidos, microempresas, considerando la base del catastro del SRI, del 2021, así Azuay con 45.814, Cañar 10.497 y Morona 
Santiago 11.300, total 67.611 microempresas de la Zona 6 del Austro, Empresas registradas en la Superintendencia de Compañías por el año 2021, Azuay 8.843, Cañar 494 y Morona Santiago 341, total 9.678, dando un gran total de 77.289, de cual se determinó el tamaño de la muestra con un 4,50\% de error, correspondiendo la muestra $n$ $=471$, mismas que fueron aplicadas mediante la herramienta Google forms, la validez de contenido fue realizado mediante el juicio de tres expertos con experiencia en el área de contabilidad, emprendimiento y metodología.

Por su parte, fue importante analizar en primer lugar, la pertinencia del coeficiente de consistencia interna de Cronbach, el misma habla, sobre el grado en que los ítems miden la homogeneidad.

Para determinar la confiabilidad del cuestionario elaborado, se procedió aplicar una prueba piloto a 30 empresas, que no forman parte de la muestra, todos ellos con características similares a los sujetos de este estudio, administrando una escala, de 30 ítems, a una muestra de $n=30$. De acuerdo con los resultados anteriores, se concluyó que la escala tiene una confiabilidad de consistencia interna muy alta, suficiente como para ser considerada fiable. En conclusión, la confiabilidad del instrumento fue de 0,9 muy alta, así mismo, fue importante la utilización de la herramienta estadística para el desarrollo de la investigación, recurriéndose a la estadística descriptiva, lo que permitió la recolección, organización y presentación de datos, facilitando, con el apoyo de cuadros, tablas y figuras, los resultados obtenidos de la aplicación de los cuestionarios en relación con los objetivos planteados del presente estudio, mediante el software libre SPSS, versión 26.

Con respecto, al procesamiento y análisis de los datos obtenidos a lo largo del proceso de investigación, se realizó, considerando el uso de la triangulación, validez, confiabilidad y contrastación de los instrumentos.

\section{Fundamentación Teórica.}

Ante la emergencia sanitaria que se ha presentado en todo el planeta tierra por la presencia del Coronavirus o COVID19, surgen otras situaciones de impacto, por la fuerza que adquirió esta pandemia, derivando en crisis de carácter contable, financiero, tributario y social, donde las oportunidades de trabajo y las actividades de las empresas, se han visto disminuidas en porcentajes alarmantes y graves. Ante esto en nuestro país, y de manera particular en la región zona 6, surge la necesidad de reprogramar y reorganizar el desarrollo productivo de las pequeñas y medianas empresas, con protocolos que permitan volver paulatinamente a la normalidad, para esto existen convenios entre entidades públicas y privadas que van configurando la nueva manera de reiniciar el trabajo en cada una de las Mipymes, con actividades comerciales, para poder enfrentar tan desfavorable situación en correcta relación con las medidas sanitarias que impidan una ola de contagio no deseada, se está impulsando muchas maneras de reactivar la producción como el teletrabajo, el trabajo por turnos, en fin una serie de estrategias innovadoras para salir de esta situación problemática. En este orden de ideas, desde el estado del arte, se abordaron 
diferentes constructos teóricos, conceptuales, legales, situacionales de la realidad que forman parte de la presente investigación, los cuales se presentan a continuación:

Según, La comisión Económica para América Latina y el Caribe- CEPAL (2018), asevera que: El término Mipyme involucra a 3 diferentes tipos de empresa: micro, pequeña y mediana, popularmente conocidas por la abreviación de Mipymes, su presencia en la estructura económica de la región es relevante, al representar un importante porcentaje de variables como producción, el empleo y el número de empresas (p.38).

La Ley Orgánica de apoyo humanitario (2020), para combatir la crisis sanitaria derivada del COVID-19, tiene por objeto establecer medidas de apoyo humanitario, necesarias para enfrentar las consecuencias derivadas de la crisis sanitaria ocasionada por el COVID19, a través de medidas tendientes a mitigar sus efectos adversos dentro del territorio ecuatoriano; que permitan fomentar la reactivación económica y productiva del Ecuador, con especial énfasis en el ser humano, la contención y reactivación de las economías familiares, empresariales, la popular y solidaria, y en el mantenimiento de las condiciones de empleo (p.6).

El estudio de esta investigación está enfocado en el área "Contable” frente al COVID- 19, ha buscado comprenderse desde distintas teorías. No obstante, para comprender esta definición, primeramente, será importante definir algunos conceptos claves en el tema de estudio, de allí que, en un tema general, podemos mencionar que el área contable es de carácter científico, social, empírico y la podemos ubicar bajo el paradigma que la contabilidad es una ciencia social, aplicada, cultural, empírica y multi-pragmatica.

En la sociedad, la contabilidad realiza una función de servicio social, esto indica que ella debe responder a las necesidades cambiantes de la sociedad y debe reflejar las condiciones culturales, económicas, legales, sociales y políticas en las cuales opera. Su utilidad técnica y social depende de su habilidad de proyectar estas condiciones, (Mejía, Mora, Montes y Montilla, 2014, p. 77).

Hendriksen (2012), propone la contabilidad como "una ciencia multiparadigma", es decir, con diversos paradigmas y diferentes comunidades científicas. Se puede presentar dos opciones según el autor, las cuales son: a) Que los paradigmas luchen entre sí por la indagación del monopolio; y, b) Que los paradigmas coexistan de forma incluyente, complementaria y no excluyente.

Según, González \& Pierre (2016), sostiene la siguiente definición de contabilidad, manifestando que es la ciencia que nos enseña a analizar, clasificar, registrar y procesar las operaciones contables que se realizan en la empresa creando un sistema de información que nos permite medir, controlar e informar sobre la situación financiera de la empresa, expresada en términos monetarios.

Por su parte, Hargadon \& Munera (1994), afirma que la contabilidad es la ciencia que trata de las actividades económicas y financieras en forma cronológica y cuantificada para 
clasificarlas, registrarlas, resumirlas en estados financieros y luego analizarlas e interpretarlas.

Así mismo, Aguirre (2020), el Consejo de Normas Internacionales de Contabilidad(IASB), consigue sus objetivos fundamentalmente a través del desarrollo y publicación de las Normas Internacionales de información financiera- (NIIF), promoviendo el uso de tales normas en los estados financieros con propósito de información general y en otra información financiera. Otra información financiera comprende la suministrada fuera de los estados financieros, que ayuda en la interpretación de un conjunto completo de estados financieros o mejora la capacidad de los usuarios para tomar decisiones económicas eficientes.

El término "información financiera" abarca los estados financieros con propósito de información general y otra información financiera.

Las NIIF establecen los requerimientos de reconocimiento, medición, presentación e información a revelar que se refieren a las transacciones y otros sucesos y condiciones que son importantes en los estados financieros con propósito de información general. También pueden establecer estos requerimientos para transacciones, sucesos y condiciones que surgen principalmente en sectores industriales específicos. Las NIIF se basan en el Marco Conceptual. Que se refiere a los conceptos subyacentes en la información presentada dentro de los estados financieros con propósito de información general.

De igual forma, Freire \& Freire (2019), sostiene que las NIIF constituyen un cuerpo único de normas mundiales de contabilidad de elevada calidad y de obligado cumplimiento, que llevan a requerir información comparable, transparente y de imagen fiel en los estados financieros para propósitos generales.

Por último, según manifiesta Puruncajas (2019), hablamos de Normas Internacionales de Contabilidad- (NIC), se puede indicar que es un conjunto de normas que reglamenta la información financiera, que debe presentarse en los correspondientes estados financieros de las organizaciones y empresas, y la forma en que debe registrarse para su respectivo análisis e interpretación.

\section{Resultados.}

En este capítulo se procede al análisis e interpretación de los resultados, según Palella y Martins (2012), la interpretación de los resultados consiste en inferir conclusiones sobre los datos codificados, basándose en las operaciones intelectuales de razonamiento lógico e imaginación, ubicando tales datos en el contexto teórico.

La interpretación de los resultados estadísticos fue un elemento crucial para la determinación de nuestras conclusiones. La tabulación e interpretación de los cuestionarios dirigidos a las Mipymes, son un total de 30 ítems, para el presente análisis se han seleccionado únicamente ocho, las más relevantes. 
Figura 1. Actividades principales de las empresas.

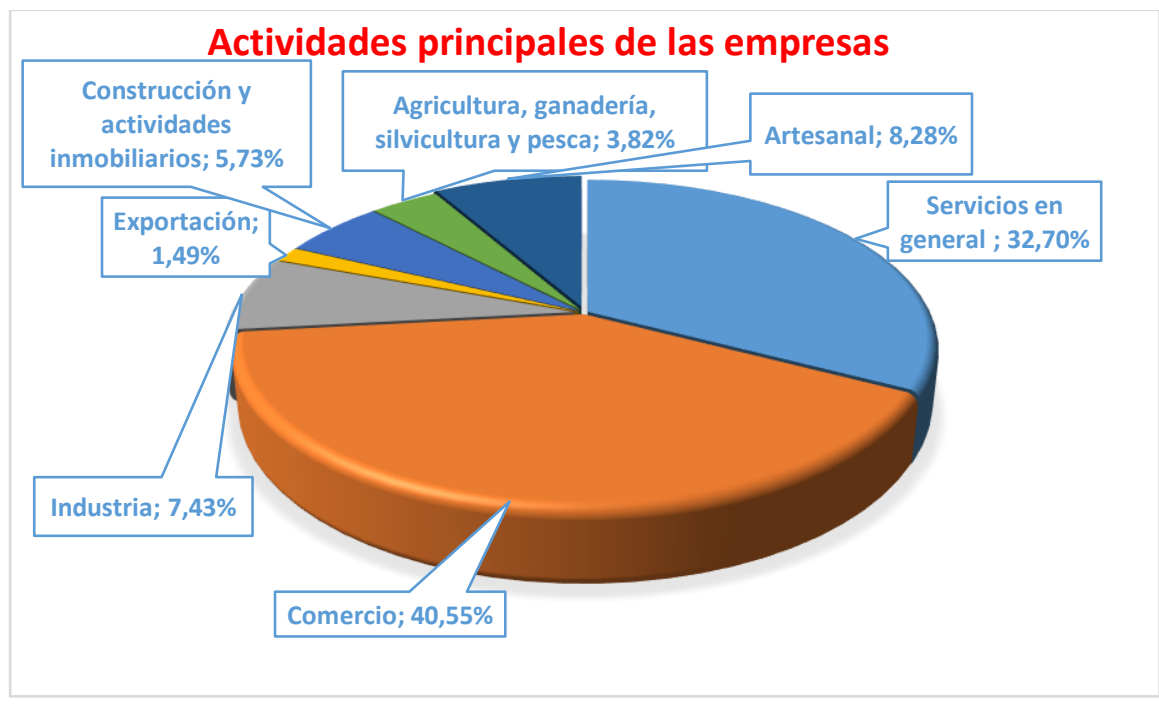

Fuente: Elaboración propia (2021).

De acuerdo al cuestionario aplicado las actividades principales de las empresas en la Zona 6, los resultados determinaron que el $40.55 \%$ empresas de Comercio, es decir: que consiste en la trasferencia e intercambio de bienes y servicios entre personas o entre entidades económicas, son las encargadas de la distribución, el traslado, almacenaje y venta, de productos. Estos datos demuestran que se deben enfocar esfuerzos para que el comercio este en constante innovación y conquistar nuevos retos tecnológicos, por su parte con el $32.70 \%$ se dedican a actividades de servicios en general, esta se encarga de brindar servicios operacionales, mantenimiento, adecuaciones e instalaciones de todo tipo, logística, marketing, ventas, este tipo de empresas han sufrido un gran golpe a sus ingresos, por estar en contacto directo con lugares o espacios de riesgo y aumentan las posibilidades de contagio del virus. Se ha podido analizar que las actividades económicas de comercio, así como servicios en general, son las más afectadas por la situación del COVID-19, en la región 6 del Austro, sumando las dos actividades económicas representan el $73.25 \%$ del total de actividades, es posible determinar que las Mipymes se encuentran afrontando serios problemas económicos.

Así, mismo con el $8.28 \%$ actividades las artesanales, $7.43 \%$ son organizaciones dedicadas a la Industria, 5.73\% actividades de construcción e inmobiliarios, 3.82\% actividades de agricultura, ganadería, silvicultura y pesca, finalmente el $1.49 \%$ se dedica a actividades de exportación, estos en un tema global nos da un 20,75\% un porcentaje considerable, estas empresas genera el pago de impuestos representativos para el estado y son pilar fundamental para fuentes de trabajo fijos, y al verse afectados por la pandemia, muchas de las familias no llevan el sustento en sus hogares, y tampoco han generado tributos. 
Figura 2. Clases de empresas.

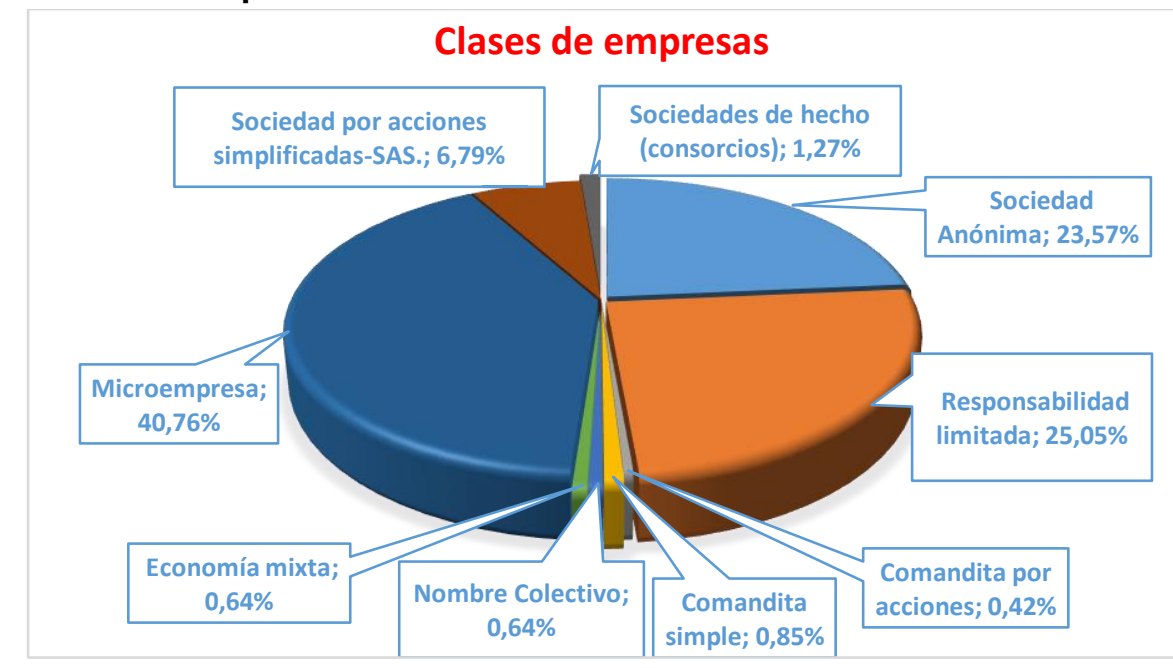

Fuente: Elaboración propia (2021).

El gráfico indica que el $40.76 \%$ de la zona de estudio son microempresas, al hablar de estas empresas en su mayoría son las que se crean a través de ideas o pequeños proyectos familiares que no buscan nada más que la supervivencia del día a día y no el fortalecimiento y expansión del negocio. Luego tenemos con un $25.05 \%$ de responsabilidad limitada, la responsabilidad de los socios con respecto al capital social se encuentra representado por participaciones, las cuales no pueden ser traspasadas por endoso, este tipo de compañías deben buscar soluciones para continuar siendo sustentables financiera y económicamente, y así evitar no fracasar.

Por otra parte, con el $23.57 \%$ están las sociedades anónimas, estas se encuentran constituidas por acciones, las que constituyen una porción de alícuota y sus acciones son transferibles, esta sociedad es una de las más fuertes, ya que la mayoría de los socios que forman parte tiene mayores acciones y son manejadas por los representantes que dirigen el rumbo de la empresa, así como las utilidades e inversiones, estas empresas tiene que enfocarse en desarrollar siempre planificaciones y estar cumpliendo con la ley, de allí que ante la presencia Covid-19, y por esta razón se debe implementar una planificación para este tipo de emergencias y buscar soluciones óptimas para afrontar las crisis, si sumamos estas dos últimas, representan el 48,62\%, de compañías controladas por la Superintendencia de Compañías, Valores y Seguros.

Así mismo el $1.27 \%$ son sociedades de hecho (consorcio), $0.85 \%$ de comandita simple, con el $0.64 \%$ las empresas de economía mixta y de nombre colectivo, sumando el 2,76\% de las empresas y demostrando así que, si bien estas empresas no tienen una gran fuerza, pero hace parte de la actividad económica.

Finalmente, con un $6.79 \%$ empresas de sociedad por acciones simplificadas-SAS. Que se han constituido en la transformación más importante del derecho societario ecuatoriano, el objetivo principal es facilitar al emprendedor en la realización de sus actividades comerciales y mercantiles y que van creciendo vertiginosamente, se constituye en un nuevo tipo societario creado recientemente en el Ecuador, mediante la Ley orgánica de 
emprendimiento e innovación (2020), lo que nos alinea en la tendencia a nivel mundial para promover nuevos emprendimientos por medio de una herramienta ágil para los empresarios.

En síntesis, todas las clases de empresas se han visto afectadas a razón de la aparición de Covid-19, sin embargo, el sector mayoritariamente golpeado por esta situación han sido las microempresas, mismas que al no contar con la suficiente liquidez y solvencia, han quedado rezagadas.

Figura 3. En el desarrollo de su gestión empresarial, como consecuencia de la reducción en la demanda y las dificultades de abastecimiento de insumos su empresa estaría inmersa en revisar.

Dificultades en el desarrollo de la gestión empresarial

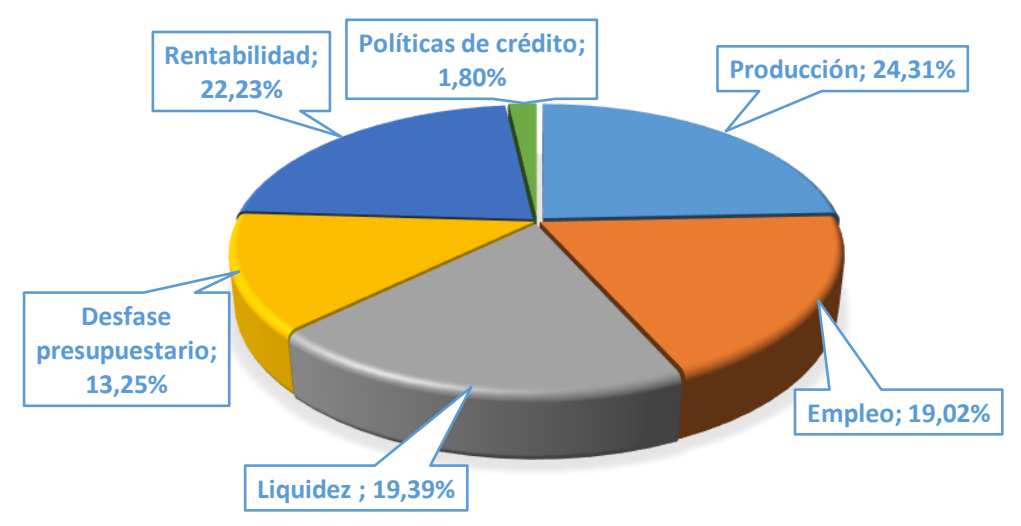

Fuente: Elaboración propia (2021).

En lo que respecta a la producción los encuestados sostuvieron en un $24,31 \%$, que es importante que las empresas puedan buscar productos o servicios sustitutivos, ya que al depender de un solo producto puede ser perjudicial para la producción que ellos pudieron haber mantenido antes del Covid-19, por tanto, será necesario la diversificación de productos.

Al referirnos a las dificultades en el desarrollo de la gestión empresarial, como primer punto es necesario revisar la rentabilidad, toda vez que el $22,23 \%$ responde que para poder afrontar la emergencia sanitaria es necesario que estas empresas deban educarse en temas financieros y análisis de riesgos, porque al poder evaluar los posibles escenarios que pueden afectar al negocio.

Las empresas la mayoría de veces deben enfrentarse a una falta de liquidez, y la gráfica refleja que un 19,39\% mostró aquello, de allí la importancia de la inyección de liquidez en las diferentes empresas, es importante ya que al no contar con el dinero suficiente para afrontar pasivos y gastos, la empresa debe cerrar y afrontar la quiebra, muchos planes de inyección financiera ofrecen las instituciones financieras, pero el riesgo es no saber si la económica podrá recuperarse en el menor tiempo posible. 
En el empleo está representada con un 19,02\%, es importante recalcar que muchos de los negocios tuvieron que hacer recorte de personal y afectaron los ingresos de los empleados y del empleador, el gobierno actual intenta solucionar el desempleo que se está atravesando en la actualidad, y por eso muchos nuevos contratos de trabajos se están llegando a implementar, de allí que el Ministerio de Trabajo promueve nuevos contratos laborales con el fin de impulsar la creación de plazas de empleo, entre estos contratos están el de emprendimiento, contrato productivo, contrato joven y de formación, y contrato turístico cultural y/o recreativo.

La información obtenida, muestra un 13,45\% un desfase presupuestario y que ocurrió un desequilibrio en sus planificaciones, esto ocasionó la redirección de los esfuerzos para que la empresa pueda mantenerse operando. Desequilibrio presupuestario y inestabilidad durante la ejecución son conceptos distintos. Un presupuesto se aprueba equilibrado, pero al no cumplirse lo deseado por el confinamiento y la disminución de las ventas, se pueden producir desequilibrios durante la ejecución del presupuesto. También hay que hacer distinciones entre presupuesto de caja, presupuesto por lo percibido y por lo devengado, en definitiva, el presupuesto es un análisis sistemático que analiza el futuro y presente de un proceso productivo y financiero de una empresa, calculando las entradas y salidas de los recursos, dinero, tiempo, NIC $\mathrm{N}^{\circ}$ 7. estado de flujo del efectivo, materiales, uso de maquinaria y equipo NIC $\mathrm{N}^{\circ} 16$. Propiedad planta y equipo.

Así mismo, un 1,80\% en políticas de crédito, ya que muchas de las entidades financieras que otorgan el crédito, no evalúan correctamente la realidad de la empresa y rechazan muchas veces los préstamos a las mismas, así como, estas entidades deben salvaguardar el dinero, los negocios deben ser responsables con la utilización del capital que deben manejar.

Figura 4. ¿Cuál es la capacidad que la entidad tiene para generar efectivo y equivalentes al efectivo, frente a la incertidumbre relativa al Covid-19?

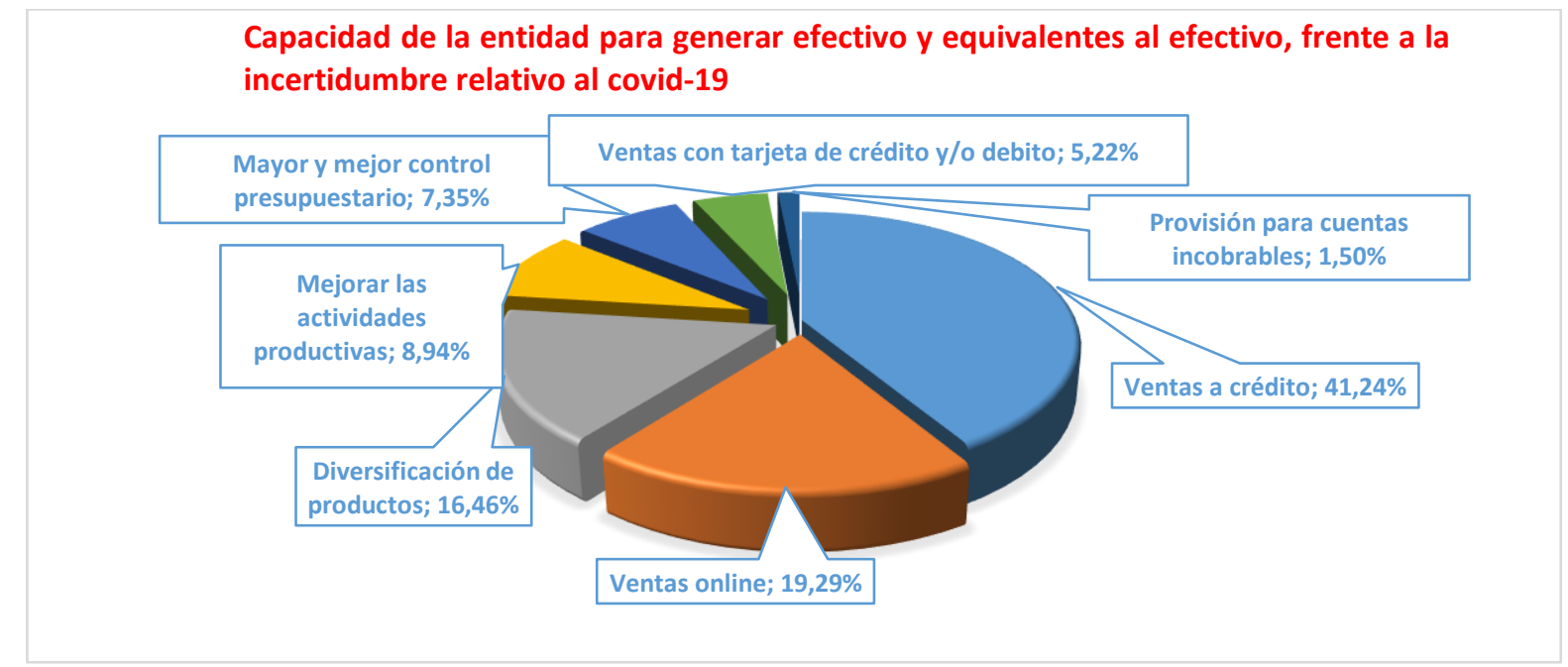

Fuente: Elaboración propia (2021).

Realizamos un análisis de cuál es la capacidad que la entidad tiene para generar efectivo o equivalentes al efectivo, articulada a la $\mathrm{NIC} \mathrm{N}^{\circ} 7$, frente a la incertidumbre relativo al 
COVID 19 y se puede observar en las estadísticas graficas que un 41,24\% representan las ventas a crédito, ya que otorga la facilidad de adquisición a los clientes y es la manera más convencional en la actualidad para comprar un bien o servicio, la venta a crédito es aquella operación donde el comprador recibe el bien o servicio y lo paga de forma aplazada en el futuro. Es decir, la venta a crédito consiste en adquirir un producto hoy y pagarlo en un periodo posterior, pero debemos estar claros que las ventas a crédito representan un riesgo, de que el cliente incumpla con su pago, por lo que las empresas deberán asegurarse que el riesgo comercial en sus ventas a crédito se puede garantizar mediante pólizas de seguro.

Por su parte, tenemos que el 19,29\% figuran las ventas online o más conocido como "ecommerce", pequeñas y grandes empresas han adoptado esta nueva modalidad, ya que uno de los canales estratégicos para general ventas hoy en día, radica en la compra y venta de productos o de servicios a través de internet, tales como redes sociales (Facebook, Twitter, WhatsApp, Instagram, YouTube, Linkedin, Medium, Quora, entre otros) y otras páginas web, lo cual significa que la modalidad de venta va evolucionando siendo esto algo positivo para el comercio en general.

Así mismo, el 16,46\% corresponde a la diversificación de productos, ya que al limitarse un poco la variedad de los mismos reduce considerablemente las oportunidades de ventas, el $8,94 \%$ pertenece a la mejora de actividades productivas, esto es resultado de la innovación y pro actividad que se genera en cada uno de los integrantes del negocio, el 7,35\% representa el mayor y mejor control presupuestario, por ello es indispensable y fundamental el proceso administrativo dentro de cualquier empresa o negocio, el 5,22\% es fruto de las ventas con tarjeta de crédito o débito, es muy importante contar con un medio de pago electrónico aumenta nuestras oportunidades de generar ingresos y por ultimo tenemos el 1,50\% para provisión de cuentas incobrables NIIF $N^{\circ}$ 9, son provisiones a tener en cuenta que radica en el hecho que por motivos ajenos a la empresa no llegan a ser canceladas por el deudor. Generando así, una pérdida de activo que ha modo contable, se le debe de dar de baja y registrar en el nuevo rubro que le corresponde.

Figura 5. ¿Los inventarios en los que se incluyen los productos terminados, comprados y almacenados para su reventa, están claramente definidos al igual que su deterioro, señale según corresponda?

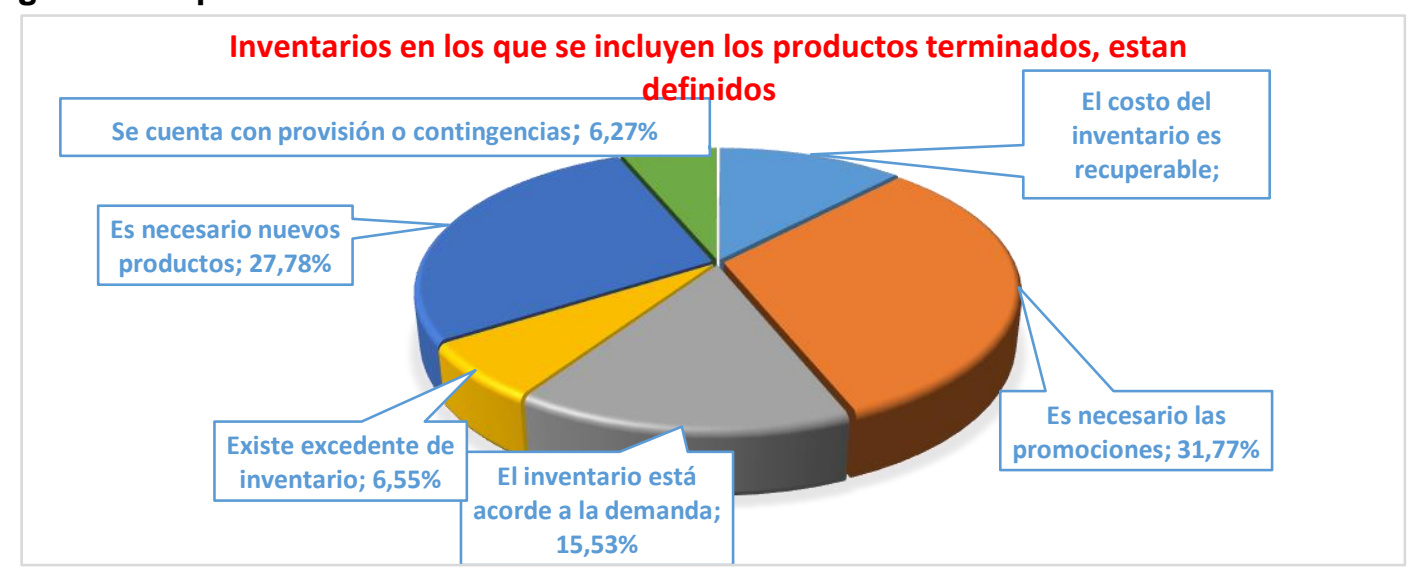

Fuente: Elaboración propia (2021). 
Basándonos en el análisis de la figura $\mathrm{N}^{\circ} 5$, en una muestra de 471 empresas encuestadas, podemos observar que con respecto a los inventarios NIC $\mathrm{N}^{\circ} 2$, en los que se incluyen los productos terminados, comprados y almacenados para su venta, un 31,77\% indica que son necesarias las promociones, ya que representa una variable de la mezcla de promoción (comunicación comercial), consiste en incentivos de corto plazo, a los consumidores, a los miembros del canal de distribución que buscan incrementar la compra o la venta de un producto o servicio.

De igual manera, el $27.78 \%$ que señala que son necesarios nuevos productos, es necesario de una cantidad de nuevos tipos de productos que se realizan. El producto consiste en ofrecer a un mercado el mismo para satisfacer sus necesidades, los nuevos productos o servicios se pueden clasificar en: Productos totalmente innovadores que crean nuevos mercados, innovaciones radicales como el internet.

El 15,53\% indica que el inventario está acorde a la demanda, no siendo este el caso de todas las empresas, puesto que no han logrado hasta el momento estabilizarse, el 12,11\% señala que el costo del inventario es recuperable, es decir el inventario es superior a su importe recuperable, que el valor que aparece registrado en la contabilidad es mayor al precio por el cual son transados en el mercado. Debido al desconocimiento por las nuevas actualizaciones generadas por las normas internacionales de información financiera. Mientras tanto, el 6,55\% de las empresas encuestadas indican que existe excedente de inventario, es decir las empresas mantienen los inventarios en existencia de la empresa, lo que indica que sus ventas han caído aproximadamente en un 50\%, ante la presencia del COVID 19, que ha ocasionado que la afluencia de consumidores sea escasa.

Por último, el 6,27\% cuenta con provisión o contingencias NIC $\mathrm{N}^{\circ} 37$, las provisiones son pasivos de cuantías inciertas y un pasivo contingente es una obligación presente que no está reconocida. Es evidente que existe una fuerte presión en el mercado para que se diversifiquen productos e implementen productos sustitutivos y que su valor sea inferior, la economía actual en el colapso con la pandemia requiere economizar y ampliar la capacidad adquisitiva vs. La economía antes de la pandemia.

Figura 6. ¿Cuál es la importancia de la capacidad de pago con respecto a pasivos financieros referente a proveedores de bienes y servicios y demás obligaciones?

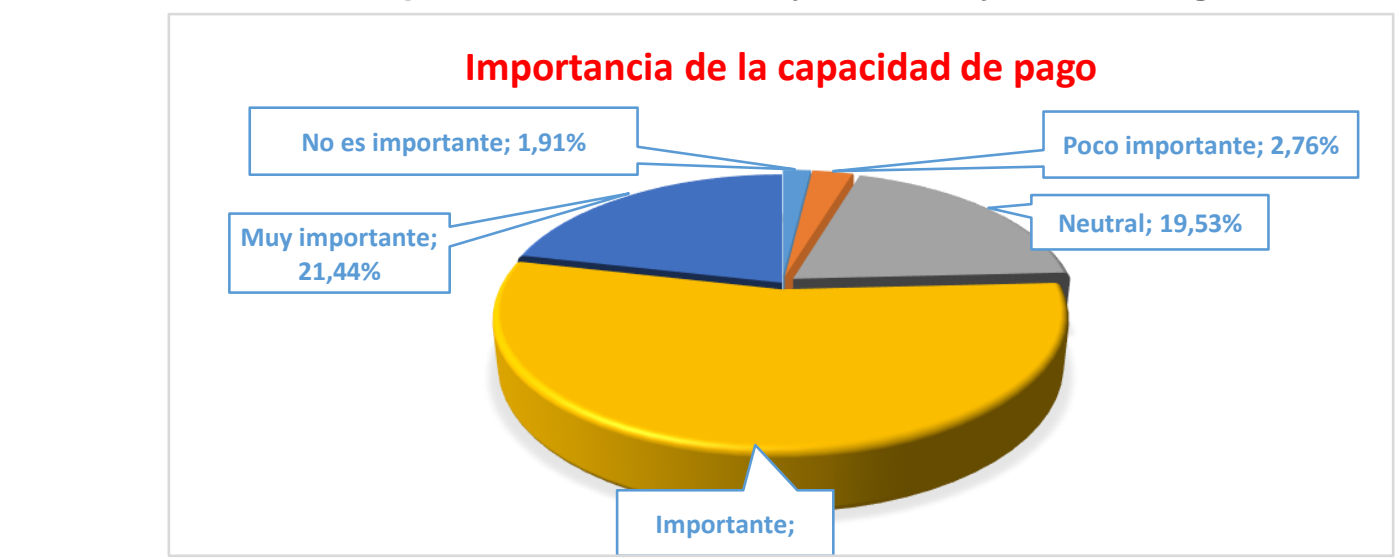

Fuente: Elaboración propia (2021). 
Enfocándonos al análisis de la gráfica $\mathrm{N}^{\circ} 6$; con relación a la importancia de la capacidad de pago con respecto a pasivos financieros referente a proveedores de bienes y servicios y demás obligaciones, es posible observar que los datos porcentuales reflejan que la mayoría de empresas representado por el 54,35\% señala que es importante, el 21,44\% indica que es muy importante, al unir ambas tendencias tenemos el 75,79\%, quienes indican la importancia que tienen una compañía para pagar sus obligaciones con sus proveedores, con las instituciones financieras y demás obligaciones.

De igual manera, el $19,53 \%$ es neutral, el $2,76 \%$ considera poco importante, finalizando con el 1,91\% que identifica como no es importante. Es claro que los dueños de Mipymes en su mayoría tienen un sentido de responsabilidad al admitir que la capacidad de pago es un asunto de gran importancia, ya que, al hacer caso omiso de ello, puede haber grandes repercusiones para la estabilidad de sus negocios.

Figura 7. Según su criterio Indique ¿Cuáles de los ingresos por actividades ordinarias, según sus transacciones está relacionada a su empresa?

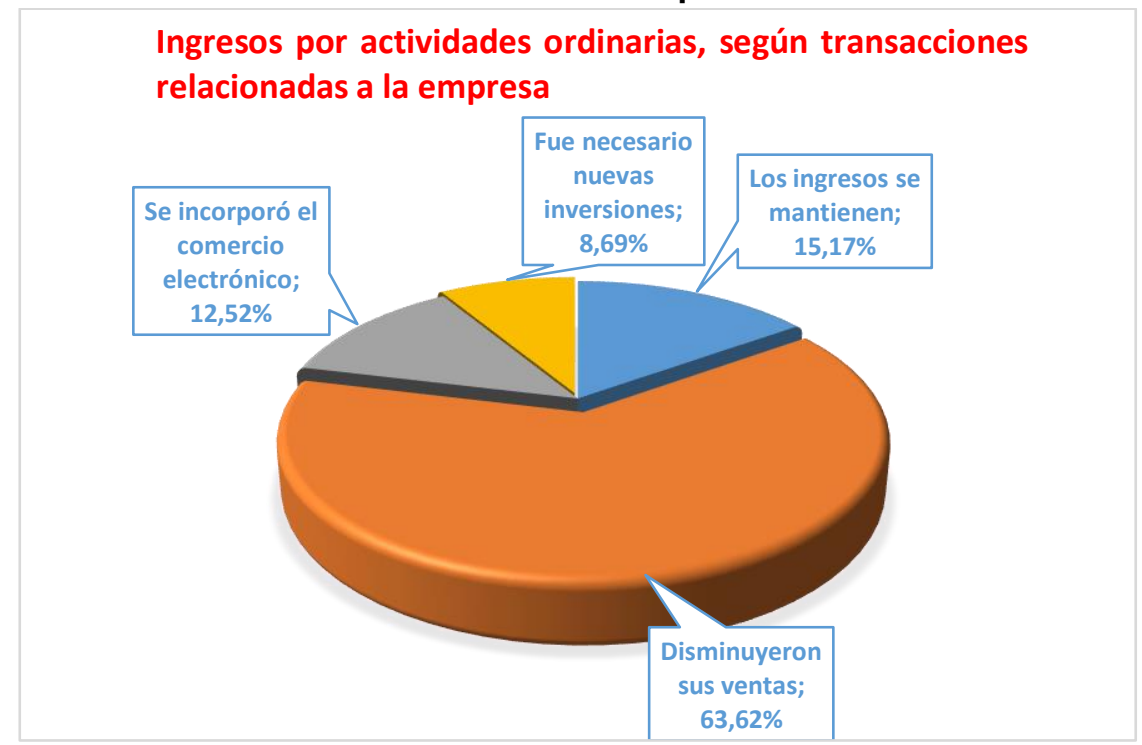

Fuente: Elaboración propia (2021).

Como se puede observar en el grafico los resultados reflejan un $63.62 \%$ en la opción que disminuyeron las ventas, esto a causa del COVID 19 y es una de las causas por las cuales muchos negocios empezaron a cerrar sus puertas, ya que dentro del tema contable les empezaba a generar perdida, de igual forma, el $15.17 \%$ en la opción que mencionaba que los ingresos NIC $\mathrm{N}^{\circ} 18$, se mantienen, y estas Mipymes generalmente corresponden a las que ofrecen productos de primera necesidad.

Por otro lado, tenemos en la opción que nos menciona que fue necesaria nuevas inversiones un valor del $8.69 \%$ esto nos indica que una pequeña cantidad decidió realizar nuevos tipos de inversiones para salvar y sostener la empresa, por último en la opción que menciona que se incorporó el comercio electrónico se puede determinar el $12.52 \%$, es decir decidieron tratar de acoplarse a la nueva forma de ventas a causa del COVID 19, de allí que las Mipymes han sido afectadas debido a la situación actual de pandemia mundial 
y han realizado ventas a través de internet lo cual ha hecho que se avance en cuanto al comercio en línea, sin embargo, existe un porcentaje de quienes han optado por hacer nuevas inversiones, para lo cual surge la incertidumbre de saber si esta ha sido o no una buena opción.

Figura 8 ¿Cuáles de los siguientes componentes, según su opinión, optó su empresa para reducir los costos?

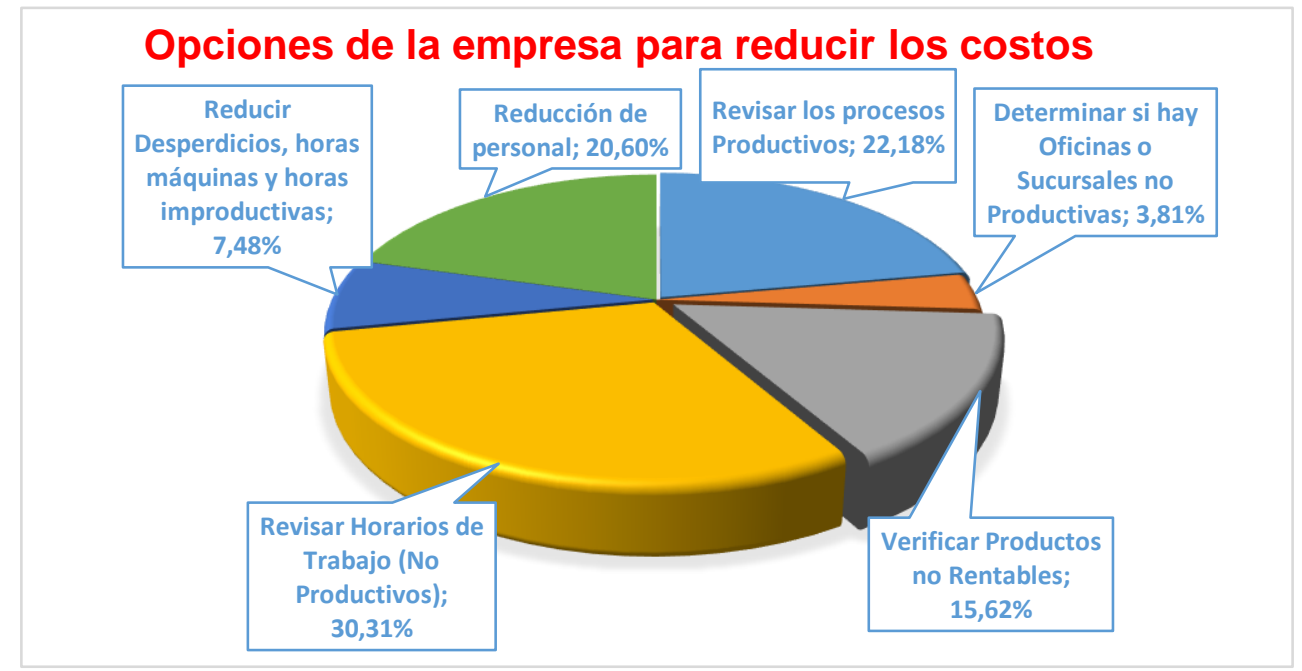

Fuente: Elaboración propia (2021).

Con respecto al analizar la opinión de los encuestados a tomar decisiones sobre la reducción de costos, articulada a la NIIF $\mathrm{N}^{\circ} 8$, sostuvieron en un $30,31 \%$ que la revisión de los horarios de trabajo, toda vez que se disminuyeron las ventas ante la presencia del COVID-19 y se hace necesario sostener la empresa, pero optimizando la fuerza de trabajo.

De la misma manera, los procesos productivos con un 22,18\%, sufriendo una reestructuración de los procesos y obligando a reducir en costos y gastos, considerando al proceso productivo como el conjunto de operaciones y fases realizadas sucesivamente y de manera planificada que son necesarias para la obtención de un bien o servicio. El proceso productivo debe tener en cuenta las características del mercado de manera que pueda ajustarse a la demanda. Así también, en un 20,60\% optaron por la reducción de su personal, estas son medidas que se sujetan a la realidad de sus negocios.

Un tema que se puede destacar es que con un $15,62 \%$ se enfoca en verificar productos no rentables, optimizando los procesos de producción y buscando nuevos productos sustitutivos. Podemos decir que un 7,48\% habla sobre el disminuir los desperdicios, horas máquinas y horas improductivas, es por ello que se redujo en el 50\% horarios de trabajo, teletrabajo, implementación de nuevos contratos y la reducción de sueldos y salarios, con el fin de evitar despidos. Finalmente, se logró determinar, con respecto a si hay oficinas o sucursales no productivas, reflejando el 3,81\%, de Mipymes que optimizaron sus recursos, para evitar gastos innecesarios. 


\section{Propuesta.}

A partir del tercer mes del año 2020, se ha vivido una situación de incertidumbre a nivel mundial hasta la actualidad marcada por la emergencia sanitaria ocasionada por el SARSCoV-2 también denominado COVID-19, este virus se detectó a finales del mes de diciembre del 2019 en la localidad de Wuhan, China a causa de un incremento anómalo de los casos por problemas respiratorios.

El Covid-19 es una enfermedad viral, caracterizada por ser de fácil transmisión, esto ha afectado a individuos, organizaciones y países a nivel mundial. En vista de ello los gobernantes de los diferentes países se vieron obligados a detener la economía, así como las actividades productivas por más de 30 días, al mismo tiempo uno de los objetivos durante la cuarentena se centraba en reducir el nivel de contagios, controlar la enfermedad $\mathrm{y}$, en última instancia, volver a la normalidad.

En Ecuador, las Mipymes juegan un papel primordial ya que son consideradas la base del desarrollo económico del país; lamentablemente a razón de lo anteriormente expuesto, las empresas confrontan problemas para mantener una estabilidad en todos los ámbitos y alcanzar un crecimiento de algún tipo; el confinamiento paralizó aproximadamente el $70 \%$ de las actividades económicas, los sectores más afectados fueron el área de manufactura, servicios, el comercial y la agricultura. En el período de marzo-junio del 2020, muchas empresas desaparecieron, esto como resultado de la pandemia y la crisis económica existente, la reducción de la producción, así como la desaparición de sus actividades ocasionaron una falta de liquidez ocasionando que estas no puedan mantenerse en operación.

Es por ello que resulta necesario conocer el estado en el que se encuentran las Mipymes, saber cómo han afrontado este gran reto que fue impuesto por COVID-19, en base a ello establecer estrategias que ayuden a su mejor desenvolvimiento contable por la pandemia del COVID-19 y las medidas de contención adoptadas están teniendo un impacto económico y social demoledor en el tejido empresarial de la Zona 6 y del país, especialmente en las Mipymes (micro, pequeñas y medianas empresas), como consecuencia de la reducción en la demanda, bajando sus niveles de producción y de empleo y tienen serios problemas de liquidez.

El presente proyecto estuvo orientado en realizar algunas tácticas contables, que son herramientas para los profesionales en finanzas, contabilidad y auditoría, que hay tener claramente definido, para poder asesorar y tomar decisiones.

Dentro de nuestro estudio, los negocios así como el trabajo tuvo un cambio radical, se generó el telemarketing, las empresas están aplicando nuevas políticas de ventas, a crédito a plazo, hablar de sesenta días era un sacrilegio en las empresas comercializadoras de bienes, actualmente están arriba de los ciento ochenta días con el afán de poder conseguir clientes, otro tema en el que se está involucrando el sector comercial e industrial es el hecho de diversificar los productos, anteriormente se fabrica un producto, hoy ese 
mismo producto se fabricará en diferentes maneras, en diferentes presentaciones, con diferentes sabor, precios, por la imaginación y la creatividad, que va a permitir mantener los negocios, además se deben mejorar las actividades productivas, algo está haciendo el gobierno de Guillermo Lasso, al respecto, es promover la reactivación económica con créditos interesantes y reducción de aranceles a materias primas, a bienes de capital, a los insumos que usan las industrias para producir, mejorar y motivar los sectores productivos.

En donde vamos a tener que poner énfasis es en un mayor y mejor control presupuestario, desde ese punto de vista las reglas han cambiado de manera significativa, de allí que todo negocio si no tiene un control presupuestario, tuvo serios problemas el año anterior y algunas Mipymes aun en el presente año, como por ejemplo las empresas del sector turístico.

Con relación a este aspecto, nos queda como profesionales asesores de empresas, conocer que le espera al empresario Ecuatoriano, que le preocupa y le interesa, el reinvento es una herramienta que vamos a tener que considerar, la preparación del profesional es fundamental, de allí que se hace necesaria la formulación oportuna de los estados financieros, porque es un factor fundamental para tomar decisiones, no hay empresa que funcione sin conocer antes su situación financiera, no solo ahora con el problema del mundo COVID, que tenemos, sino en todo el tiempo, la formulación de los estados financieros tiene que ser oportuna, no se puede tomar decisiones si los mismos no están listos al menos en los cinco primeros días del mes subsiguiente, tal como lo determina la Norma Internacional de Contabilidad $\mathrm{N}^{\circ} 1$, con relación a la presentación de los estados financieros, y fundamental que incluya elementos importantes y relevantes de la contabilidad, a través de las notas aclaratorias a los estados financieros.

Según, la situación financiera la analizamos a través del estado de situación financiera y el estado de cambios en el patrimonio para conocer las fortalezas que tienen las empresas, el rendimiento financiero para saber si realmente estamos ganando o estamos perdiendo, es el estado de resultados integrales que es base, además como herramienta financiera tenemos el presupuesto, no solo de operación sino de inversión, es importante que las empresas que lo aplican, debe también tener el flujo de caja, alimentando en base a cobranzas, considerando los ingresos en base o función a los pagos que tiene que realizar la compañía. De igual manera, el flujo de efectivo como estado financiero va ser el resultado de lo que se está documentando para que la administración sepa, como se está utilizando los recursos, a través de operaciones, financiamiento, e inversión y las notas aclaratorias para cuando cualesquier lector de los estados financieros, conozca en qué situación se encuentra la empresa, que tipos de contingencias hay, sea laboral, societario, que incertidumbre tiene la compañía, con respecto a tales y cuales productos, entre otros temas, de allí que es importante para que de manera oportuna se tome las decisiones pertinentes.

Con respecto al contenido contable, fue necesario analizar a especie de un barrido en las principales cuentas de los estados financieros y en consonancia con lo que sostiene la 
Norma Internacional de Contabilidad, así por ejemplo para el caso de las inversiones temporales, el Contador, Gerente financiero, los Auditores, debemos estar plenamente identificados con la NIC $\mathrm{N}^{\circ}$, allí reza textualmente lo se tiene que hacer, igual ocurre con los activos financieros, que debe realizarse en cumplimiento a lo que dice la NIC $\mathrm{N}^{\circ}$, en semejanza y en conjunto con la Norma Internacional de Información Financiera, que es la NIIF $\mathrm{N}^{\circ}$, habla de la provisión para cuentas incobrables, es un capitulo que se indagó en la presente investigación, lo que trajo como resultado que se debía hacer provisiones importantes al 31 de diciembre del 2020, el párrafo B5 de la NIIF $\mathrm{N}^{\circ}$, nos dice como tenemos que ir haciendo las provisiones del deterioro de esas cuentas por cobrar, que en muchos casos se convirtieron en cuentas incobrables, para ello es importante que el área financiera tenga, la información para que la administración vaya conociendo los problemas, una cartera clasificada por edades, donde haya la cartera corriente y vencida a 30, 60, 90, 180 y 360 días, que tipo de garantía tengo sobre esa cartera, que certeza y conocimiento tengo, del negocio de mi deudor, son informaciones importantes, que se debe tener a la mano, de tal suerte que en un país como el nuestro en donde tenemos, cuentas de clientes por cobrar, la normativa nos da todas la luces para ir tomando las decisiones con respecto a este tema.

Los inventarios ahora llamados existencias, según las NIC $\mathrm{N}^{\circ} 2$, están claramente definidos al igual que su deterioro, para provisión para inventarios en mal estado, a través de la NIC $\mathrm{N}^{\circ} 2$, que son normas que los responsables del manejo financiero debemos estar familiarizados para cumplir con esa exigencia en el proceso contable y tener consecuentemente estados financieros confiables.

Igualmente, para lo que es propiedad planta y equipo NIC $\mathrm{N}^{\circ} 16$, nos da los insumos básicos, no solamente para el reconocimiento del activo, sino para el tratamiento contable, esta cuenta que es muy importante especialmente en el sector industrial.

Ahora nos corresponde ver la parte del pasivo, donde los pasivos financieros le corresponde a la NIC $\mathrm{N}^{\circ} 39$, así como los pasivos principalmente con proveedores, la Norma Internacional de Contabilidad $\mathrm{N}^{\circ} 1$, y para lo que es beneficios sociales, está la NIC $\mathrm{N}^{\circ} 19$, donde nos da las pautas del registro, hay que cumplir con lo que dispone la Súper Intendencia de Compañías para las provisiones por desahucio y jubilación, de manera paralela el reconocimiento de gastos, de conformidad a lo que nos dice el Servicio de Rentas Internas.

Por el lado del patrimonio, hay que tener cuidado con lo que dice la NIC $\mathrm{N}^{\circ} 1$ y 32 , con respecto al capital al igual que la reserva legal y otros resultados integrales, y el tema de súperavit por valuación de propiedades planta y equipo, que debe cumplir con las disposiciones de los organismos de control, para lo que son avalúos, la norma dice que hay que revalorizar por lo menos cada cinco años no menos de tres y en la práctica en las Pymes esto se está cumpliendo, hay casos que dicen yo no revalorizo, porque eso me genera más costos en el momento de la depreciación, allí ya se cae en otro campo, que es en el del auditor externo, que tendrá que calificar a que si es o no aplicable establecer una apreciación en el dictamen de auditoria. 
Por el lado de los ingresos es muy importante no introducir como hacíamos en el pasado de considerar todo en una sola bolsa, en el estado de resultados, si no que ahora clasificamos ingresos ordinarios, conforme la NIC $\mathrm{N}^{\circ} 18$ y extraordinarios, conforme lo establecen las NIIF $\mathrm{N}^{\circ} 15$ y NIIF $\mathrm{N}^{\circ} 8$, respectivamente, en donde está claramente definido, el costo de venta que no es solo un tema que tenemos que basarnos en la NIC $\mathrm{N}^{\circ} 2$, si no en aspectos operativos de la compañía, si es un empresa comercial el costo de ventas, es un tema muy rápido de definirlo, pero si estamos hablando de una empresa industrial, en donde tenemos diferentes componentes como es la materia prima y los materiales, los gastos de fabricación y la mano de obra, hay que afinar bien el lápiz a ver si esos costos de ventas están bien determinados y que consecuentemente, provoquen un impacto muy significativo en el estado de resultados integrales.

Lo que corresponde a los gastos, la misma norma lo determina la $\mathrm{NIC} \mathrm{N}^{\circ} 1$, por norma general vamos a reconocer gastos cuando se registra, así como los ingresos cuando se realizan. Con respecto a los gastos es fundamental guardar consistencia con la normativa tributaria que rige el País, para poder determinar cuáles son los gastos tributarios y cuáles son los exentos, de tal manera que podamos tener una información meridianamente clara, con respecto a determinar que gastos son deducibles y que gastos no lo son.

\section{Conclusiones.}

A continuación, se exponen las principales conclusiones, integrando los resultados de los cuestionarios, y la técnica de la observación:

- Del análisis de los gráficos $\mathrm{N}^{\circ} 1,2$ y 3 respectivamente, se sostiene que la actividad principal es el comercio con el 40,55\%, que la microempresa con el 40,76\%, desempeña un papel fundamental en nuestra realidad económica y podemos agregar que un 59,24\% de estas empresas forman parte de la sociedad mercantil, cumpliendo con deberes y obligaciones, y que los puntos de mayor interés para las Mipymes y que han tenido que afrontar fueron, la producción con el 24,31\%, la rentabilidad con el 22,23\%, la liquidez con él 19,39\%, el empleo con el 19,02\%, y desfase presupuestario con el $13,25 \%$, ya que debido a la emergencia sanitaria han tenido que tomar decisiones muy firmes para mantenerse unas en el mercado y otras han tenido que cerrar sus puertas.

- Con un enfoque dirigido al ámbito económico y contable, basándonos en los resultados arrojados de las 471 empresas encuestadas podemos mencionar que dichas empresas y gran parte de la economía necesita reinventarse y proponer alternativas con relación a nuevos productos o equivalentes que cubran las mismas necesidades, puesto que la pandemia ha provocado una contracción notoria en la economía, habiendo generado por tanto el telemarketing, nuevas políticas de ventas a crédito, como se demuestra en grafica $\mathrm{N}^{\circ} 4$ en el 41,24\%, y ventas online en un 19,29\% con el afán de poder conseguir clientes, es importante también el involucramiento del sector comercial e industrial en la diversificación de productos y servicios en un 16,46\%, considerando la invención, imaginación y la 
creatividad, que permitirá mantener los negocios, igualmente se hace necesario mejorar las actividades productivas, así como se refleja en el gráfico $\mathrm{N}^{\circ} 5$, es necesario persuadir a los consumidores y usuarios mediante promociones en el $31,77 \%$, de allí que el resultado de este análisis muestra que las empresas tienen una alta capacidad de generar efectivo o sus equivalentes, pues claro esta como han venido adaptándose a esta nueva realidad frente al Covid-19 sin perder sus oportunidades de negocio, todos los resultados en proporción a su gestión, pro actividad y planificación pues han sabido identificar los medios y estrategias para seguir operando en el mercado.

- En base a la variable “¿Cuáles de los ingresos por actividades ordinarias, según sus transacciones está relacionada a su empresa?" podemos dejar como resultado que el $63,62 \%$, según grafico $\mathrm{N}^{\circ} 7$, disminuyó sus ventas, por tanto generaron perdidas dentro de su estado de resultados ya que una pequeña cantidad decidió actualizar sus ventas, otras tuvieron el privilegio de mantener los ingresos y otras tuvieron que acceder a nuevas inversiones sin embargo consideran la importancia de la capacidad de pago, según el grafico $\mathrm{N}^{\circ} 6$, en un 75,79\%, de allí que se espera que con la reactivación económica y la propuestas realizadas al menos el $40 \%$ de empresas que estaban dentro del rango de perdidas salgan de ese nivel y empiecen a mantener sus ventas o mejoren sus ingresos.

- Así también, quienes dirigen las empresas que fueron encuestadas, reflejan que se tuvo que tomar decisiones que pueden encaminar a sus negocios a mantenerse en el mercado competitivo o de cerrar sus negocios, siendo primordial la supervivencia, han tenido que enfrentarse conforme la gráfica $\mathrm{N}^{\circ} 8$, revisar horarios de trabajo en el 30,31\%, reducción de personal en el 20,60\%, revisar los procesos productivos en un 22,18\% y la verificación de productos no rentables en el 15,62\% entre lo más relevante, con el afán de recortar recursos, costo y gastos, para mantenerse y ser sustentables económica y financieramente.

- De la investigación se determina que los estados financieros preparados bajo NIIF, dan mayor confianza a los accionistas, administradores, empleados, organismos de control y terceros usuarios de la información financiera de las empresas. De allí que las Normas Internacionales de Información Financiera son lineamientos aplicables a todo tipo de industrias, negocios y actividades en el mundo, y están orientadas en una buena parte a las Mipymes, por tanto en nuestro país se debe aplicar las normas más comunes relacionadas con las principales cuentas del balance y considerando siempre el principio de materialidad; tales como: cuentas y documentos por cobrar, inventarios, activos fijos, inversiones, cargos diferidos, pasivos laborales, ingresos y gastos, entre otras.

- Por su parte, los Contadores y Auditores debemos cumplir estrictamente con la aplicación de la normativa contable internacional que ha sido dispuesta por la Superintendencia de Compañías, para el caso de la Mipymes, como componente fundamental es importante el análisis de las normas y principios generales de la Contabilidad, el control presupuestario, analizar el financiamiento de las actividades como son los recursos propios y de terceros que permiten desarrollar la estructura completa de la información financiera, así como los diferentes ajustes 
contables que permitan proporcionar información confiable y real a los usuarios, para una correcta toma de decisiones, ante la pandemia del COVID-19.

- La información recogida permitió determinar que el Contador es el encargado de las actividades económicas y financieras en forma moderna e integral, el contador actual no solo es un contador de cuentas contables, que realiza declaraciones tributarias, su campo de acción es mucho más amplio, los contadores son consultores, asesores de negocios, manejan normativas, prestan diferentes servicios como auditores internos y externos, manejo y análisis de datos, Big data, manejo y control de presupuestos, pericias contables y muchas más actividades que requieren las Mipymes.

\section{Referencias bibliográficas.}

Arias, F. (2016). El Proyecto de Investigación: Introducción a la metodología científica. ( $7^{a}$ Edición), Caracas - Venezuela. Editorial El pasillo, C.A.

Aguirre, N. (2020). Niif para las Pymes, Normas Internacionales de información Financiera para Pequeñas y medianas Entidades (Pymes), Quito- Ecuador. Editorial Aguirre y Asociados Cía. Ltda.

Freire, J., \& Freire, V. (2019). Guía de implementación práctica sobre la implementación de la NIIF en el Ecuador. Quito-Ecuador. Editorial Dimedios.

González, D., \& Pierre, P. (2016). La contabilidad administrativa y la toma de decisiones Financieras. Guayaquil-Ecuador. Editorial ULVR. 94 p.

Hargadon, B., \& Múnera, A. (1994). Principios de Contabilidad, (4ta edición), Colombia. Editorial Norma S.A.

Hendriksen, E. (2012). Teoría de la contabilidad. República de México, Editorial Uthea.

La Comisión Económica para América Latina - CEPAL (2018), Perspectivas económicas de América Latina 2018: Repensando las instituciones para el desarrollo, Edición. OCDE, Paris.

Ley Orgánica de apoyo humanitario (2020). Gaceta oficial $N^{\circ} 229$, del 22 de junio del 2020.

Ley Orgánica de Emprendimiento e Innovación, (2020), publicada en el Suplemento del Gaceta Oficial N ${ }^{\circ} 151$, del 28 de febrero del 2020.

Mejía, E., Mora, G., Montes, C., \& Montilla, O. (2014), Marco Conceptual de la biocontabilidad. Sinapsis (6), 147-178. 77

Palella y Martins (2003). Metodología de la investigación cuantitativa. Fondo editorial de la Universidad Pedagógica Experimental Libertador. 
Puruncjas, M. (2019). Normas Internacionales de Información Financiera NIIF, Casos prácticos y analizados para Pymes. (9 $9^{\mathrm{a}}$ Edición). Quito-Ecuador. Editorial Publicont ediciones contables.

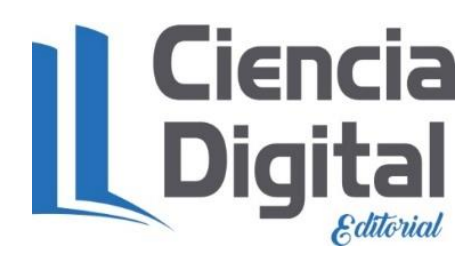




\section{PARA CITAR EL ARTÍCULO INDEXADO.}

Becerra Molina, E., Jaramillo Calle, Y., \& Astudillo Arias, P. (2021). La importancia de la información contable ante la incertidumbre del Covid-19, en las Mipymes en el entorno de los negocios en la región 6 . Visionario Digital, 5(3), 111-132. https://doi.org/10.33262/visionariodigital.v5i3.1779

\section{LCiencia}

El artículo que se publica es de exclusiva responsabilidad de los autores y no necesariamente reflejan el pensamiento de la Revista Visionario Digital.

El artículo queda en propiedad de la revista y, por tanto, su publicación parcial y/o total en otro medio tiene que ser autorizado por el director de la Revista Visionario Digital.
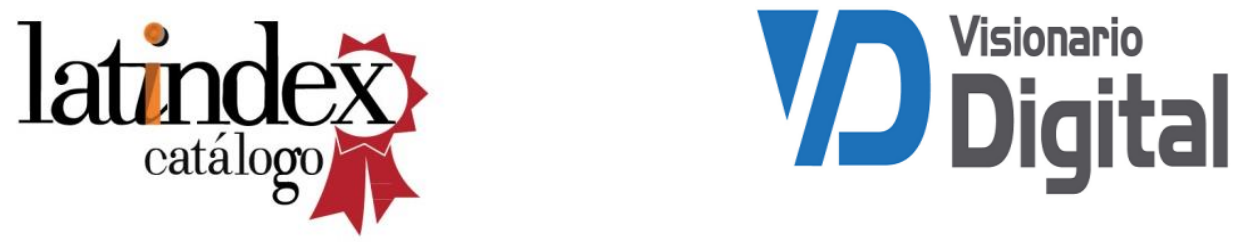